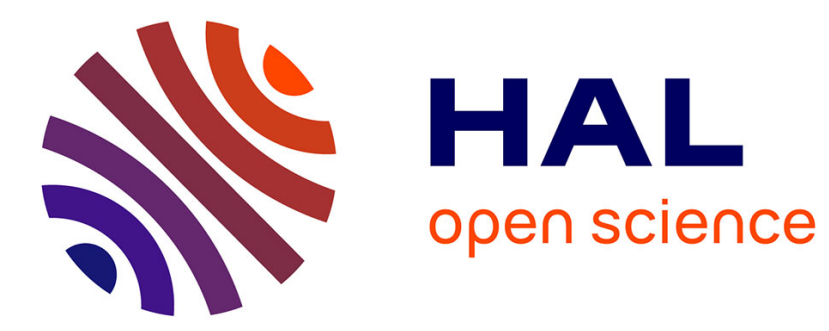

\title{
Quality control of commercial cranberry products: HPTLC-densitometry a new deal
}

Leslie Boudesocque-Delaye, Arnaud Lanoue, Joëlle Dorat, Alain Gueiffier, Frank Bruyère, Cécile Enguehard-Gueiffier

\section{- To cite this version:}

Leslie Boudesocque-Delaye, Arnaud Lanoue, Joëlle Dorat, Alain Gueiffier, Frank Bruyère, et al.. Quality control of commercial cranberry products: HPTLC-densitometry a new deal. Food Control, 2018, 86, pp.214-223. 10.1016/j.foodcont.2017.11.017 . hal-02176754

\section{HAL Id: hal-02176754 \\ https://hal.science/hal-02176754}

Submitted on 8 Jul 2019

HAL is a multi-disciplinary open access archive for the deposit and dissemination of scientific research documents, whether they are published or not. The documents may come from teaching and research institutions in France or abroad, or from public or private research centers.
L'archive ouverte pluridisciplinaire HAL, est destinée au dépôt et à la diffusion de documents scientifiques de niveau recherche, publiés ou non, émanant des établissements d'enseignement et de recherche français ou étrangers, des laboratoires publics ou privés. 


\section{Quality control of commercial cranberry products: HPTLC-densitometry a}

\section{2 new deal}

3 Leslie Boudesocque-Delaye ${ }^{\mathrm{a}}$, Arnaud Lanoue ${ }^{\mathrm{b}}$, Joëlle Dorat ${ }^{\mathrm{a}}$, Frank Bruyère ${ }^{\mathrm{c}}$, Alain

4 Gueiffier $^{\mathrm{d}}$, Cécile Enguehard-Gueiffier*,d

5 a UMR INRA 1282 Infectiologie et Santé Publique, Equipe Recherche et Innovation en

6 Chimie Médicinale, Université François Rabelais de Tours, UFR des Sciences

7 Pharmaceutiques, 31 avenue Monge, 37200 Tours, France

8 b EA 2106 Biomolécules Biotechnologies Végétales, Université François Rabelais de Tours,

9 UFR des Sciences Pharmaceutiques, 31 avenue Monge, 37200 Tours, France

$10{ }^{\mathrm{c}}$ Service Urologie, Université François Rabelais de Tours, CHRU de Tours, 37044 Tours

11 cedex 9, France

${ }^{\text {d }}$ UMR INSERM 1069 Nutrition Croissance et Cancer, Université François Rabelais de

13 Tours, UFR des Sciences Pharmaceutiques, 31 avenue Monge, 37200 Tours, France

Corresponding author: cecile.gueiffier@univ-tours.fr,

$$
\text { phone }+33(0) 247367172
$$




\section{Quality control of commercial cranberry products: HPTLC-densitometry a}

\section{new deal}

Leslie Boudesocque-Delaye $^{\mathrm{a}}$, Arnaud Lanoue ${ }^{\mathrm{b}}$, Joëlle Dorat ${ }^{\mathrm{a}}$, Frank Bruyère ${ }^{\mathrm{c}}$, Alain

Gueiffier $^{\mathrm{d}}$, Cécile Enguehard-Gueiffier*,d

${ }^{\text {a }}$ UMR INRA 1282 Infectiologie et Santé Publique, Equipe Recherche et Innovation en Chimie Médicinale, Université François Rabelais de Tours, UFR des Sciences

Pharmaceutiques, 31 avenue Monge, 37200 Tours, France

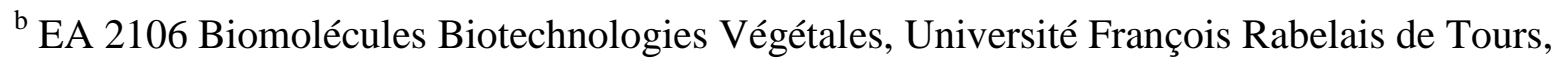
UFR des Sciences Pharmaceutiques, 31 avenue Monge, 37200 Tours, France

${ }^{c}$ Service Urologie, Université François Rabelais de Tours, CHRU de Tours, 37044 Tours cedex 9, France

${ }^{\text {d }}$ UMR INSERM 1069 Nutrition Croissance et Cancer, Université François Rabelais de Tours, UFR des Sciences Pharmaceutiques, 31 avenue Monge, 37200 Tours, France

Corresponding author: cecile.gueiffier@univ-tours.fr, phone $+33(0) 247367172$ fax $+33(0) 236477144$ 
A fast quality control protocol based on reference BL-DMAC assay and High-performance thin-layer chromatography (HPTLC)-Densitometry was optimized for routine quality control of cranberry (Vaccinium macrocarpon) products. The sample preparation appeared as a key step to ensure a relevant comparison of products quality and biological data. Sequential solid/liquid extractions were required to fully extract polyphenols, regardless the extraction solvent chosen. The HPTLC-densitometry herein protocol used epicatechin, PAC- $\mathrm{A}_{2}$ and PAC- $B_{2}$ as quality markers and densitometric measurements at $200 \mathrm{~nm}$. The PAC$\mathrm{A}_{2} /$ Epicatechin ratio, obtained using HPTLC, appeared as an appropriate indicator of the quality of cranberry ingredient. Only two products, among the tested panel, exhibited a high quality cranberry-based ingredient using this criteria. UPLC-MS analyses coupled to multivariate analyses confirmed HPTLC-densitometry conclusions. This work highlighted the plural PAC composition of commercial products and the lack of standardization for cranberry-based products on the market, explaining the non-reproducibility of clinical trials.

Keywords: cranberry; HPTLC; UPLC-MS; Proanthocyanidin; quality control Epicatechin (PubChem CID: 72276), Catechin (PubChem CID: 73160), Proanthocyanidin $A_{2}$ (PubChem CID: 124025), Proanthocyanidin B 2 (PubChem CID: 122738), 4dimethylaminocinnamaldehyde (PubChem CID: 5284506)

\section{Cranberry (Vaccinium macrocarpon Ait.) is a red fruit well-known for its high polyphenol} content. Cranberry extracts are complex mixtures of sugars, flavonoids, anthocyanins and condensed tannins also called proanthocyanidins (PACs) (Howell, 2007). PACs are oligomers or polymers of flavan-3-ol basic elements, typically catechin or epicatechin (Gu et al., 2004). 
A-type PACs of cranberry focused scientists' attention since the beginning of 2000's in various biomedical fields, like cardiovascular diseases (Rodrigez-Mateos et al., 2016), biofilm prevention (Girardot et al., 2014), diabetes (Kowalska \& Olejnik, 2016 ), etc. Among them, the most studied activity of cranberry's PACs is the potential benefit in prevention of recurrent urinary tract infections (UTI). In this case A-PACs seem to play a key role by preventing binding of Escherichia coli to urinary mucosa (Howell, 2007; Iswaldi et al., 2012).

Avorn, Monane, Gurwitz, Glynn, Choodnoskiy and Lipsitz (1994) demonstrated a positive effect on bacteriuria and pyuria of the consumption of $300 \mathrm{~mL}$ of cranberry juice per day. This work was used to determine the reference active dose of PACs that was set at $36 \mathrm{mg}$ of PACs per day, using reference method called BL-DMAC (4-dimethylaminocinnamaldehyde). In 2009, the European Food Safety Authority (EFSA, 2009) endorsed the preventive effect of the consumption of cranberry juice or other cranberry products on UTI. Following this official recognition, many nutraceutical products containing cranberry ingredients were put on the market for urinary track health. These commercials products are very heterogeneous regarding forms and ingredients (Sánchez-Patán, Bartolome, Martín-Alvaréz., Anderson, Howell, Monagas, 2012).

The multiplication of cranberry containing products led to a multiplication of clinical trials, with conflicting results as stated by the Agence nationale de sécurité sanitaire de l'alimentation, de l'environnement et du travail (ANSES) in 2011, the Cochrane review in 2012 (Jepson, William \& Craig, 2012), and also recently in JAMA (Nicole, 2016). They pointed out heterogeneity of age at enrolment of the patients, consumed dose or ingested form (juice, capsules or tablets). But the major drawback highlighted, especially by Jepson et al. (2012), was the lack of characterization of cranberry active ingredient in most of the trials, and therefore a possible misused of the product at ineffective dose. Actually in most of the trials the dose of PACs found in the cranberry ingredient was not specified (Jepson et al., 
2012) or inferior to the recommended dose (Juthani-Mehta, Perley, Chen, Dziura \& Gupta, 2010; Beerepoot et al., 2011).

As mentioned before, the recommended daily PACs dose of $36 \mathrm{mg} /$ day was determined using the official reference method called BL-DMAC (Prior et al., 2010). BL-DMAC is based on the selective reaction of DMAC reagent with flavan-3-ol, such as epicatechin, and quantitation using a PAC- $\mathrm{A}_{2}$ (commercial dimeric PAC) calibration curve (Hümmer \& Schreier, 2008). BL-DMAC allowed the estimation of global PACs content but without any discrimination between cranberry A-PACs and common B-PACs widely distributed in vegetable kingdom (grape, cocoa, heather...). Moreover, while DMAC reagent gives an intense reaction with flavanol monomers (catechin, epicatechin), it reacts only with the terminal monomer of oligomeric PACs, leading to their underestimation (Krueger et al., 2016). Recent data demonstrated that the use of dimeric PAC- $\mathrm{A}_{2}$ as calibration standard leads to dramatic underestimation of PAC content and suggested the use of a standardized cranberry extract (c-PAC) for calibration curves (Krueger et al, 2016). However, the main disadvantage here was the limited commercial availability of this new standard and the impossibility to compare with the reference dose (36 mg of PACs /day). Anyway, even more accurate, the DMAC protocol does not give any information on PAC profile.

In some trials, the active PACs from cranberry were deeper analysed using high resolution analyses, like HPLC-fluorimeter-mass spectroscopy (Beereport et al., 2011), which were not affordable for routine control. Again the obtained value could not be compared to the reference dose of $36 \mathrm{mg}$ of PACs.

A fast quantitative method for quality control of cranberry juice was recently developed in our laboratory using High-performance thin-layer chromatography (HPTLC)-densitometry (Boudesocque, Dorat, Pothier, Gueiffier, Enguehard-Gueiffier, 2013). This method allows the rapid quantitation of three quality markers (catechin, PAC- $\mathrm{A}_{2}$ and PAC- $\mathrm{B}_{1}$ ) in one step 
without tedious sample conditioning like thiolytic degradation (Kimura, Ogawa, Akihiro, Yokota, 2011) or acidic degradation and derivatization with phloroglucinol (Hümmer \& Schreier, 2008). Combined with BL-DMAC, quality assessment of cranberry juice was more accurate, considering both global PAC titration (BL-DMAC) and PAC profile (HPTLCdensitometry). This strategy was successfully applied for the characterization of processed cranberry juices (Rozoy, Boudesocque, Bazinet, 2015), but was never applied to the analysis of commercial products.

Commercial products usually contained a wide variety of excipients, like sugars, organic acids, mineral salt, that could disturb HPTLC analysis during sample application or migration. Moreover, in some product, cranberry ingredients were adsorbed on silica or maltodextrine, which should be removed prior to analysis. Also commercial products often contained multiple PACs sources, which could interfere with the analysis. Sample preparation of commercial cranberry products was then challenging.

Some publications reported the analysis of active pharmaceutical ingredient in commercial tablets using HPTLC-densitometry, such as tapentadol or lomefloxacin. In all cases a solid/liquid extraction followed by filtration or centrifugation was necessary prior to analysis (Rajasree, Radha, Shyni, Girija \& Nair, 2013; Pragati, Manisha \& Prakruti, 2014). In our case the challenge would be higher since the complex polyphenol fraction would have to be totally recovered.

Cranberry based commercial products put on the market exhibited a high variability of PAC ingredient, usually containing a mixture of PAC sources beside cranberry. Considering this variability, it is reasonable to state that the unique solid/liquid extraction step certainly led to a bias, due to partial extraction of PACs, which made product comparison almost irrelevant. In this work we proposed a general procedure for sample preparation ensuring a total extraction of the global polyphenol fraction of all products. The second part of the work 
presented herein was the optimization of previously reported HPTLC protocol designed for highly concentrated pure cranberry juice or extract (Boudesocque et al., 2013). Low PACs content and/or higher rate of B-type PACs, found in some commercial products, imposed to increase the sensitivity and to optimize the mobile phase. Finally a panel of commercials products were compared using BL-DMAC procedure in combination with optimized HPTLCdensitometry protocol: only two of them were found of good quality. UPLC-MS was then performed to validate our conclusions.

\section{Materials and methods}

\subsection{Chemicals}

Catechin, epicatechin, proanthocyanidin $\mathrm{A}_{2}\left(\mathrm{PAC}-\mathrm{A}_{2}\right)$ and proanthocyanidin $\mathrm{B}_{2}\left(\mathrm{PAC}-\mathrm{B}_{2}\right)$ standards were purchased from Extrasynthèse (Genay, France). 4dimethylaminocinnamaldehyde (DMAC), Amberlite XAD 16 resin and anisaldehyde were purchased from Sigma Aldrich (St Louis, MO, USA). Hydrochloric acid, formic acid, methylene chloride $\left(\mathrm{CH}_{2} \mathrm{Cl}_{2}\right)$, ethyl acetate (EtOAc), methanol $(\mathrm{MeOH})$ and acetone were purchased from Carlo Erba (Val de Reuil, France). Water was purified by a Milli-Q-system (Millipore Corporation, Bedford, MA, USA).

\subsection{Cranberry juice}

The cranberry juice was a pasteurized and clarified raw cranberry juice produced by Fruit d'Or (Notre-Dame-de-Lourdes, QC, Canada). The juice was stored at $-28{ }^{\circ} \mathrm{C}$ and thawed out at $4{ }^{\circ} \mathrm{C}$.

\subsection{Commercial cranberry products}

Ten different commercial cranberry products, presented as stick powder, powder capsules, tablets and syrups were purchased from French pharmaceutical market. Four products $(\mathbf{1}, \mathbf{2}, \mathbf{4}$ and 6) were reported to contain an additional PAC source (grape, blueberry, heather or tea 
extract), as indicated on the label. Products $\mathbf{2}$ and $\mathbf{9}$ contained an additional anthocyanin source (hibiscus extract). Product 7 contained also propolis. (Table 1).

Insert here table 1

\subsection{Commercial samples preparation}

Sample preparation protocol was resumed in Figure 1.

\section{Insert here Figure 1}

Tablets, grounded manually, and powder of capsules (around $1.2 \mathrm{~g}$ ) were mixed with $45 \mathrm{~mL}$ of extraction solvent: water, $\mathrm{MeOH} 0.1 \% \mathrm{HCl}$ or acetone/acetic acid/water (75:0.5:24.5, v/v/v) (Acetone Mix). Then samples were sonicated during $30 \mathrm{~min}$ in an ultrasonic bath RK $100 \mathrm{H}$ (Bandelin electronic, Berlin, Germany), and centrifuged $5 \mathrm{~min}$ at $4000 \mathrm{rpm}$ (Rotofix 32A, Hettich, Bäch, Switzerland). The supernatant was recovered and the solid residue extracted again with $45 \mathrm{~mL}$ of solvent. After every S/L extraction, $5 \mathrm{mg}$ of solid residue were mixed with $1 \mathrm{~mL}$ of acidic DMAC reagent and vortexed $1 \mathrm{~min}$. Absorbance at $640 \mathrm{~nm}$ $\left(A_{640 \mathrm{~nm}}\right)$ of the supernatant was measured after $15 \mathrm{~min}$ of contact. The solid/liquid extraction step was repeated until the $A_{640 n m}$ value was below 0.05 .

All supernatants were pooled and concentrated under vacuum, and then solubilized in a minimum volume of water (10-20 mL). Sticks powder and syrup were simply diluted in water.

All samples and fresh cranberry juice were then subjected to Amberlite ${ }^{\circledR}$ XAD 16 column (30 cm high, $3.5 \mathrm{~cm}$ diameter). The column was first washed with $800 \mathrm{~mL}$ of water to eliminate sugars and hydrophilic excipients. Then the polyphenolic fraction of the different products was recovered by elution with $600 \mathrm{~mL}$ of $\mathrm{MeOH}$. The $\mathrm{MeOH}$ fraction was dried under vacuum and used for further analysis, this fraction was labelled as Total Polyphenolic Extract (TPE).

All extractions were performed in triplicate. 


\subsection{BL-DMAC procedure}

The BL-DMAC protocol used was previously described by Prior et al. (2010). Standard solutions of PAC- $\mathrm{A}_{2}$ were prepared by diluting stock solution in $\mathrm{MeOH}$ to reach concentrations of 5,10, 25 and $50 \mu \mathrm{g} / \mathrm{mL}$. Absorbance measurements were performed at 640 nm by a microplate reader Multiskan GO 3.2 (Thermofisher, Villebon sur Yvette, France). TPEs were solubilized in acetone/water $(50: 50, \mathrm{v} / \mathrm{v})$ to obtain solutions of concentrations ranging from 2.5 to $10 \mathrm{mg} / \mathrm{mL}$ for commercial products (Table S3), and of $8 \mathrm{mg} / \mathrm{mL}$ for cranberry juice. These solutions were then diluted ten-fold in $\mathrm{MeOH}$. $\mathrm{MeOH}$ blanks were used.

Results were obtained in $\mu \mathrm{g}$ of PACs and converted into $\mu \mathrm{g}$ of PACs per $100 \mathrm{mg}$ of corresponding TPE, using sample solution concentration $(\mathrm{mg} / \mathrm{mL})$.

\subsection{High-performance thin-layer chromatography}

A CAMAG (CAMAG, Muttenz, Switzerland) HPTLC instrumental set-up consisting of a sample applicator Linomat 5, Reprostar 3, Scanner 3 and Digistore 2 Documentation system was used for the analyses. The data were managed by the software platform winCats 1.4.2 Planar Chromatography Manager.

HPTLC Silica Gel $60 \mathrm{~F}_{254}, 20 \mathrm{~cm}$ x $10 \mathrm{~cm}$ (Merck, Darmstadt, Germany) were employed and developed in a CAMAG Automatic Developing Chamber ADC2.

\subsubsection{Chromatographic procedure}

Standard and sample solutions were applied bandwise (band length $6 \mathrm{~mm}, 80 \mathrm{~nL} / \mathrm{s}$ delivery speed, track distance $10.7 \mathrm{~mm}$ and distance from the edge $20 \mathrm{~mm}$, under 6 bar of nitrogen pressure). Standard solutions were applied in duplicate; spiked and sample solutions were applied in triplicate. Plates were developed with $\mathrm{CH}_{2} \mathrm{Cl}_{2}$ :EtOAc:formic acid (6:10:2, v/v) as mobile phase (migration distance $8.5 \mathrm{~mm}$ ), at room temperature, with humidity between 40 and $60 \%$, after a 15 min plate preconditioning with mobile phase and tank saturation. 
After densitometric analysis, plates were then stained by spraying sulphuric anisaldehyde solution and dried at $100^{\circ} \mathrm{C}$ during 2 min on a CAMAG TLC plates Heater 3. Epicatechin, PAC- $\mathrm{A}_{2}$ and PAC-B $\mathrm{B}_{2}$ appeared in orange and red colour.

\subsubsection{Standards}

Epicatechin, PAC-B ${ }_{2}$ and PAC- $\mathrm{A}_{2}$ standard stock solutions (1 mg/mL of each compound) were prepared by dissolving the appropriate amount of each compound in $\mathrm{MeOH}$. Stock solutions were stored at $-18^{\circ} \mathrm{C}$, in the dark and were stable for 6 months.

For the calibration curve, four standard solutions $(0.02,0.03,0.05$ and $0.07 \mathrm{mg} / \mathrm{ml})$ were obtained by diluting the stock solution in $\mathrm{MeOH}$.

$5 \mu \mathrm{L}$ of each solution were applied, corresponding to $0.1,0.15,0.25$ and $0.35 \mu \mathrm{g}$ of each compound.

\subsubsection{Sample solutions}

TPEs were solubilized with acetone/water $(50: 50, \mathrm{v} / \mathrm{v})$ in order to obtain solutions of concentrations ranging from 2.5 to $80 \mathrm{mg} / \mathrm{mL}$ (Table S3), for commercial products, and of 40 $\mathrm{mg} / \mathrm{mL}$ for cranberry juice. $5 \mu \mathrm{L}$ of solution were applied.

\subsubsection{Spiked solutions}

$1 \mathrm{~mL}$ of product 5 TPE solution at 2.5 and $5 \mathrm{mg} / \mathrm{mL}$ was mixed with $1 \mathrm{~mL}$ of standards solution at $0.02,0.03$ or $0.04 \mathrm{mg} / \mathrm{mL}$ and then evaporated to dryness. The solid residue was suspended in $1 \mathrm{~mL}$ of acetone/water (50:50, v/v) and used for the analysis. $5 \mu \mathrm{L}$ of each solution were applied corresponding to added amount of $0.1,0.15$ and $0.2 \mu \mathrm{g}$ of each compound.

\subsubsection{Densitometric measurements}

Visual inspection and documentation of the chromatograms were carried out under white light at wavelengths of 366 and $254 \mathrm{~nm}$ with Reprostar 3. Densitometric determinations were performed in absorbance mode at $200 \mathrm{~nm}$ using the TLC Scanner 3 without derivatization. 
The evaluation was assumed by the area under the curve (AUC) measurement towards a calibration curve of each standard.

Results were obtained in $\mu \mathrm{g}$ of standard in the applied sample and converted in $\mu \mathrm{g}$ of standard per $100 \mathrm{mg}$ of corresponding TPE, using applied volume and sample solution concentration $(\mathrm{mg} / \mathrm{mL})$.

UV spectra of standards and spots exhibiting the same $R_{F}$ than standards were registered between 190 and $700 \mathrm{~nm}$ and compared to confirm their identity.

\subsection{Metabolic profiling by UPLC-MS}

UPLC was performed using a Waters ACQUITY-UPLC ${ }^{\text {TM }}$ system coupled to a SQD mass spectrometer equipped with an electrospray ionization (ESI) source controlled by Masslynx 4.1 software (Waters, Milford, MA). Sample separations were performed on a Waters Acquity HSS T3 C18 column $(150 \mathrm{~mm} \times 2.1 \mathrm{~mm}$, i.d. $1.8 \mu \mathrm{m})$ with a flow rate of $0.4 \mathrm{~mL} / \mathrm{min}$ at $55^{\circ} \mathrm{C}$. The injection volume was $5 \mu \mathrm{L}$. Mass spectrometry detection was performed in $\mathrm{ES}^{-}$mode with a linear elution gradient of acetonitrile-water-formic acid (5:95:0.1 to 40:60:0.1) over 18 min. The capillary and sample cone voltages were $3,000 \mathrm{~V}$ and $30 \mathrm{~V}$, respectively. The cone and desolvation gas flow rates were 60 and $800 \mathrm{Lh}^{-1}$. Data were collected using the selected ion monitoring (SIM) mode for flavan-3-ols $\left([\mathrm{M}-\mathrm{H}]^{-}=m / z\right.$ 289), dimeric PAC-A types $([\mathrm{M}-$ $\mathrm{H}]^{-}=m / z$ 575), trimeric PAC-A types $\left([\mathrm{M}-\mathrm{H}]^{-}=m / z\right.$ 863) and dimeric PAC-B types $\left([\mathrm{M}-\mathrm{H}]^{-}\right.$ $=m / z$ 577) and processed by the QuanLynx ${ }^{\mathrm{TM}}$ software (Waters, Milford, MA). SIM chromatograms at $\mathrm{m} / z 289$ showed two peaks corresponding to catechin $(\mathrm{RT}=5.37 \mathrm{~min})$ and epicatechin $(\mathrm{RT}=6.94 \mathrm{~min}), \mathrm{SIM}$ chromatograms at $\mathrm{m} / \mathrm{z} 575$ showed three peaks including PAC-A $A_{2}(R T=10.22 \mathrm{~min})$, SIM chromatogram at $\mathrm{m} / z$ 577 showed five peaks including PAC$\mathrm{B}_{2}(\mathrm{RT}=6.29 \mathrm{~min})$ and SIM chromatograms at $\mathrm{m} / \mathrm{z} 863$ showed two peaks.

\subsection{Statistical validation}


Statistical validation was performed using accuracy profile (Feinberg, 2007). A statistical analysis of HPTLC and DMAC assay datas was performed using one way ANOVA analysis of variance test followed by a Tuckey comparison between groups. The $p$ values $\leq 0.05$ were considered as significant.

Principal Component Analysis (PCA) was performed using SIMCA P+ version 12.0 (Umetrics AB, Umeå, Sweden). All variables were mean-centered and unit-variance (UV) scaled prior to PCA.

\section{Results and Discussion}

Few studies reported quality assessment of commercial cranberry products (Lee, 2013; Prior et al, 2010; Sánchez-Patán et al., 2012). Sánchez-Patán et al. (2012) compared commercial products containing mainly cranberry ingredient. They determined the total polyphenol and PAC contents of each product. They concluded that some products failed to fulfil the recommended daily PACs dose of $36 \mathrm{mg} /$ day. Lee (2013) compared PAC-A 2 content of products after a multistep purification process. In these works, the solid/liquid extraction step was reduced to a single step extraction with MeOH 0.1\% (Sánchez-Patán et al., 2012) or acetone mixture (Lee, 2013; Prior et al, 2010). A wide variety of cranberry commercial products are found on the market with a high diversity of polyphenol sources (cranberry, grape seeds, blueberry...), of cranberry ingredient (fruit powder, extract...) and of galenic formulations (syrup, tablets...). Considering this variability, it is reasonable to state that the unique solid/liquid extraction step certainly led to a bias, due to partial extraction of PACs, which made products comparison almost irrelevant to compare biological or clinical data.

\subsection{Products selection}

To be representative of the real market for cranberry based nutraceuticals, ten products were selected including various galenic forms, various cranberry ingredients and for half of them 
additional PAC sources (Table 1). Previous studies were mainly limited to product containing only cranberry ingredients (Lee, 2013; Prior et al, 2010; Sánchez-Patán et al., 2012) but the major adulteration/falsification risk comes from products containing multiple PAC sources.

\subsection{Sample preparation: solid/liquid extraction optimization}

Quality control of commercial products sold as tablets or capsules (all products except products $\mathbf{1}$ and 2) is usually based on two main steps: a solid/liquid extraction of target compounds followed by an elimination of solid residue (Rajasree et al., 2013; Pragati et al., 2014).

In this work the sample preparation optimization followed several constraints: 1) All PACs should be totally recovered from the commercial product; 2) Mineral and sugar-based excipients that could disturb UV spectroscopy and/or HPTLC analysis should be removed; 3) Polyphenol profile should be as close as possible of native ingredients.

\subsubsection{Total extraction of PACs}

In the literature, two main solvents were reported for the extraction of cranberry based product: MeOH 0.1\% (Sánchez-Patán et al., 2012) or acetone/acetic acid/water (75:0.5:24.5, v/v) (Acetone Mix) (Prior et al., 2010). In both cases, products were extracted only once and insoluble fraction was removed by centrifugation.

Considering the chemical variety of PACs, one solid/liquid extraction step was probably not enough to totally extract monomers, oligomers, and polymers. To validate this hypothesis, product 7, containing only cranberry ingredient as polyphenol source, was extracted once, twice and three folds with Acetone Mix using ultrasonic extraction. For each extraction, BLDMAC assay was performed on the resulting extracts and solid residues. Results showed an increase of global PACs content in the resulting extracts as function of extraction steps: from $3.2 \%(\mathrm{w} / \mathrm{w})$ to $7.7 \%(\mathrm{w} / \mathrm{w})$ for one to three extractions. In addition, the residues demonstrated a decrease of the absorbance at $640 \mathrm{~nm}\left(A_{640 \mathrm{~nm}}\right)$ from 1.5 to 0.157 . These results 
confirmed that one single solid/liquid extraction was irrelevant to compare global PACs content of commercial products, since most of the PACs were not extracted after only one extraction.

Consequently, based on those results, it was decided to repeat the solid/liquid extraction step as long as the solid residue reacted with DMAC reagent and led to supernatant $A_{640 \mathrm{~nm}}$ above 0.05 . Three extraction solvents were screened: water, Acetone Mix and $\mathrm{MeOH} 0.1 \%$ $\mathrm{HCl}$.

The number of solid/liquid extraction required for total recovery of extractible PACs was dramatically variable, from 3 (products 4 and 6) to 18 extractions (product 9). No correlation appeared between cranberry ingredient nature and the required number of extraction steps: products 5, $\mathbf{6}$ and $\mathbf{1 0}$ containing cranberry concentrated juice powder needed 5, 4 and 10 extractions respectively; products $4,7,8$ and 9 containing cranberry extract required 3, 5, 5 and 18 extractions respectively. Considering product $\mathbf{9}$, the high number of extractions required could be attributed to the presence of a hibiscus extract and its high content in anthocyanins that could interfere with $A_{640 \mathrm{~nm}}$ measurement. The required number of extraction was then not predictable, and could not be homogenized. Consequently, a standardized procedure should then include the DMAC control of solid residue, with $A_{640 n m}$ value of 0.05 as the reference to detect complete extraction.

\subsubsection{Disturbing excipients elimination}

The main disturbing excipients were salts, like magnesium stearate or calcium phosphate, which could precipitate during BL-DMAC analysis, and sugar based ingredient, like sucralose or maltodextrin, which were well known to disturb analytes' elution on HPTLC plates.

To remove those non-phenolic metabolites, extracts were subjected to Amberlite XAD-16 resin. XAD-16 is a polyaromatic resin that retains polyphenol compounds by $\pi$-stacking interactions. Non-phenolic compounds (salts, sugars...) were first eluted using deionized 
water then polyphenols were eluted using $\mathrm{MeOH}$. The resulting methanolic fraction was labelled as Total Polyphenols Extract (TPE).

The recovery of PACs was validated by subjected a known amount of catechin to the same protocol, in triplicate. Recovery rates for catechin were ranging from $98.0 \%$ to $98.5 \%$ with a relative standard deviation (\%RSD) of 0.01 .

\subsubsection{Optimal conditions selection}

Extraction yields, global PACs contents (TPE) and daily PACs amount of each product were resumed in Table 2.

\section{Insert here Table 2}

From these results, it clearly appeared that the optimal solvent was different depending on the product: water gave the higher extraction rate of three products $(\mathbf{3}, \mathbf{5}, \mathbf{1 0})$, Acetone Mix of five products $(4,6,7,9,10)$ and acidic $\mathrm{MeOH}$ of six products $(\mathbf{3}, \mathbf{4}, \mathbf{7}, \mathbf{8}, \mathbf{9}, \mathbf{1 0})$.

It was also important to note that for six products, the different solvents gave sometimes not statistically different results. For example, considering product $\mathbf{1 0}$ the total PACs found in recommended daily intake was $11 \mathrm{mg}$ with all solvents.

The Acetone Mix was often equivalent to acidic $\mathrm{MeOH}(p$ value $>0.05)$ and did not give any side reaction, like depolymerisation of some PACs observed with acidic $\mathrm{MeOH}$. So the Acetone Mix extracts were chosen for further analysis.

Those results highlighted the key role of the solid/liquid extraction in cranberry products control, especially the number of repetitions, for an accurate extraction and then an accurate comparison.

TPE of all products, resulting of Acetone Mix extraction, were subjected to HPTLCdensitometry analyses to analyse PACs profile.

\subsection{HPTLC-densitometry optimization}

\subsubsection{Detection}


The low PACs content of some extracts required an optimization of former HPTLCdensitometry protocol (Boudesocque et al., 2013). This protocol used calibration curves ranging from 0.7 to $5 \mu \mathrm{g}$ of catechin, $\mathrm{PAC}-\mathrm{A}_{2}$ and $\mathrm{PAC}-\mathrm{B}_{1}$, which was classical range according to HPTLC standard when a derivatization step was required (Boudesocque et al., 2013). In order to enhance the sensitivity of the method, the HPTLC plates were analysed using a TLC scanner at $200 \mathrm{~nm}$, corresponding to the maximum absorption of PACs. Under these conditions, the sensitivity was increased by 7 folds, allowing the use of calibration curves ranging from 0.1 to $0.35 \mu \mathrm{g}$, suitable for low concentrated extracts.

\subsubsection{Mobile phase}

Since cranberry extracts analysed in the present study may contain other PACs sources like grape or blueberry (B-type PACs), the previously described mobile phase

$\mathrm{CH}_{2} \mathrm{Cl}_{2} / \mathrm{EtOAc/Formic} \mathrm{acid} \mathrm{(6:10:1,} \mathrm{v/v)} \mathrm{(Boudesocque} \mathrm{et} \mathrm{al.,} \mathrm{2013)} \mathrm{was} \mathrm{optimized} \mathrm{to}$ enhance the retardation factor $\left(\mathrm{R}_{\mathrm{F}}\right)$ of dimeric PAC-B used as standard.

Indeed, during analyses of methanolic extract of product $\mathbf{6}$ using the former mobile phase $\mathrm{CH}_{2} \mathrm{Cl}_{2} /$ EtOAc/Formic acid (6:10:1, v/v), the quantitation of the dimeric PAC-B was disturbed by the high amount of higher molecular weight PACs, exhibiting closely related $\mathrm{R}_{\mathrm{F}}$. By increasing formic acid ratio to 2 in the mobile phase and increasing saturation time of the tank, $\mathrm{R}_{\mathrm{F}}$ of the dimeric PAC-B was increased and the separation from higher molecular weight PACs was improved, allowing its accurate quantification. For economic reasons, PAC- $\mathrm{B}_{1}$ was replaced by PAC- $\mathrm{B}_{2}$, as widespread and having the same $\mathrm{R}_{\mathrm{F}}$ in these conditions. For all samples, the identity of PAC- $\mathrm{A}_{2}$ and PAC- $\mathrm{B}_{2}$ was checked by comparing UV spectra of TLC spot with the reference spectra of standards. When UV spectra were matching, the spot was considered as PAC-A $\mathrm{A}_{2}$ or PAC-B $\mathrm{B}_{2}$, if not the spot was not quantitated (See Figure S1 and S2, Supplementary material). 
The use of this new mobile phase $\left(\mathrm{CH}_{2} \mathrm{Cl}_{2} / \mathrm{EtOAc/formic} \mathrm{acid,} \mathrm{6:10:2,} \mathrm{v/v)} \mathrm{allowed} \mathrm{the}\right.$ clear separation of catechin and epicatechin, with a $\mathrm{R}_{\mathrm{F}}$ difference of 0.1 on HPTLC plate. The quantification of each separated standard was then possible, contrary to the global monomer assessment previously reported (Boudesocque et al., 2013). Since cranberry PACs are mainly composed of epicatechin polymers, epicatechin was then used as standard monomer, instead of catechin.

Anthocyanins and high molecular weight PACs stayed at the start zone of the HPTLC plate, and appeared as red spots after derivatization.

\subsubsection{Statistical validation}

The optimized HPTLC-densitometry protocol had to be first statistically validated. As previously reported, the accuracy profile was used to validate our analytical procedure (Feinberg, 2007). The acceptance limits could be decreased at $5 \%$ since derivatization step was eliminated for quantitation. The accuracy profiles of each standard (epicatechin, PAC- $\mathrm{A}_{2}$, PAC-B $_{2}$ ) (Figure S3) demonstrated the high reproducibility and robustness of our HPTLCdensitometry protocol.

Spiked samples were analysed using product 5 extract, containing the higher amounts of epicatechin and PAC- $\mathrm{A}_{2}$, as reference matrix. The values obtained were accurate with bias around 0.5 , from the theoretical value. All validation data are available in the Supplementary material (Tables S1 and S2, Figures S3 and S4).

The HPTLC-densitometry protocol was then validated and the screening of the ten commercial products TPE proceeded.

\subsection{Commercial products screening}

After the ingredient extraction, all commercial products TPEs were analysed by both BLDMAC and HPTLC-densitometry and compared to a fresh cranberry juice (Table 3). In order to compare all products, global PACs, quality markers (epicatechin, PAC- $\mathrm{A}_{2}$ and PAC- $\mathrm{B}_{2}$ ) 
contents and $\mathrm{PAC}-\mathrm{A}_{2} /$ epicatechin ratio for each product were related to the recommended daily intake. Considering the cranberry juice, the daily dose was fixed at $300 \mathrm{~mL}$, based on the intake recommendation done by Avorn et al. (1994).

\section{Insert here Table 3}

\subsubsection{Global PACs content (BL-DMAC)}

The reference cranberry juice fulfilled the daily intake of $36 \mathrm{mg}$ of PACs, in the $300 \mathrm{~mL}$ of juice. Four products $(\mathbf{1}, \mathbf{5}, \mathbf{6}$ and 7) complied with the recommended dose of $36 \mathrm{mg}$ of PACs per day. Products 2, 3, 4, 8, 9 and 10 contained lower amounts of PACs corresponding to an intake between $4.4 \mathrm{mg}(\mathbf{3})$ to $23 \mathrm{mg}(\mathbf{9})$ of PACs per day.

These results demonstrated the difference between all commercial products in term of global polyphenols content. This difference could explain the clinical variation observed with the different cranberry based products.

At this step, products $\mathbf{1}$ and $\mathbf{6}$ appeared as the best ones, considering global PACs intake, but it is important to note that both contained a mix of PACs sources, leading possibly to adulteration with inactive PACs.

\subsubsection{Quality markers content (HPTLC-Densitometry)}

All TPE (commercials products and juice) were subjected to HPTLC analysis and as we could expect dramatic differences were highlighted.

Reference cranberry juice showed an amount of PAC- $\mathrm{A}_{2}$ twice higher than epicatechin $\left(\right.$ PAC- $\mathrm{A}_{2} /$ Epicat. $\left.=2.38\right)$. PAC-B $\mathrm{B}_{2}$ was detected but not quantified (amount lower than LOQ). This quality markers profile would be considered as a reference profile, to attest cranberry ingredient quality.

Considering first PACs profile of highly concentrated product (products 1, 5, 6 and 7), HPTLC-densitometry protocol highlighted the dramatic disparity between products (Figure 2 and Table 3). 
Product 5 exhibited good amounts of epicatechin and PAC- $\mathrm{A}_{2}$, in almost the same ratio than the reference cranberry juice $\left(\mathrm{PAC}-\mathrm{A}_{2} /\right.$ Epicat.=2.35). This cranberry ingredient seemed to be

441

442

of high quality, without any adulteration. Product 8, with lower global PACs amount, exhibited a similar PAC profile than product 5, considering the PAC- $\mathrm{A}_{2} /$ Epicat. ratio (2.10). Product 7 contained epicatechin and PAC- $\mathrm{A}_{2}$ in equivalent amounts (ratio of 1), which differed from the cranberry reference profile. This might indicated a partial degradation of PACs of this product.

Product 1, exhibiting the highest daily intake of PACs, showed only a small epicatechin amount but exhibited intense spots of intermediate $\mathrm{R}_{\mathrm{F}}$ between PAC- $\mathrm{B}_{2}$ and PAC- $\mathrm{A}_{2}$. The authenticity of the cranberry ingredient was then questionable, especially considering the absence of PAC- $\mathrm{A}_{2}$.

Product 6 containing both grape seed and cranberry as PACs sources, presented on HPTLC (Figure 2) a high amount of PAC-B $2(8.4 \mathrm{mg})$, matching UV spectra (Figure S1), assessing the presence of B-type PACs. Catechin was also found in higher amount than epicatechin (2.18 and $1.65 \mathrm{mg}$ respectively). PAC- $\mathrm{A}_{2}$ content was 10 folds lower than PAC-B 2 (0.8 and $8.4 \mathrm{mg}$ respectively), it was then reasonable to conclude that grape seed PACs, which are recognized to be inactive in UTI, were predominant in this product. Then the high daily PACs intake $(43.6 \mathrm{mg}$ ) for product 6 could be considered as mostly constituted of inactive PACs. It was also interesting to note that PAC- $\mathrm{A}_{2} /$ Epicat. ratio was also low, with a value around 0.5 , highlighting the poor quality of the cranberry ingredient found in this product.

Products 2, 3, 4, 9 and 10 exhibited low amounts of all markers, which was consistent with their low global PACs contents. Surprisingly, product 4, composed of a mixture of PACs sources (cranberry, blueberry, heather), exhibited the lowest amounts of markers $(0.1 \mathrm{mg}$ of 
epicatechin, $0.05 \mathrm{mg}$ of PAC- $\mathrm{A}_{2}$, no quantifiable PAC-B ${ }_{2}$ ), indicating the poor quality of polyphenol ingredients used.

In this study, the PAC- $\mathrm{A}_{2} /$ Epicat. ratio appeared as a good indicator of PACs ingredient quality: a PAC- $\mathrm{A}_{2} /$ Epicat. ratio $\geq 2$ was indicative of a high quality cranberry ingredient, like for product 5 or $\mathbf{8}$.

\subsubsection{Polyphenols profile (UPLC-MS)}

To go further in the chemical characterization of the cranberry products and to validate the HPTLC results on cranberry-based ingredient of commercial products panel, UPLC-MS analysis targeted on flavan-3-ol basic elements $(\mathrm{m} / \mathrm{z} 289)$, dimeric $(\mathrm{m} / \mathrm{z} 575)$ and trimeric $(\mathrm{m} / \mathrm{z}$ 863) PAC-A types and dimeric PAC-B types $(\mathrm{m} / z$ 577) were performed and compared to the chemical profile of the reference juice. Principal component analysis (PCA) was performed as unsupervised clustering to show similarity and differences among the proanthocyanidin compositions. The PCA score plot of the two first components shown in Figure 3A explained $90.6 \%$ of the variation with $65.5 \%$ explained by first principal component (PC1) and $25.1 \%$ by PC2.

\section{Insert here figure 3}

The loading plot showed that the PACs were responsible for the discrimination of the cranberry products (Figure 3B). PC1 was mainly influenced by dimeric and trimeric PAC-A types ( $\mathrm{m} / \mathrm{z}, 575$ and 863$)$, while PC2 was influenced by monomeric flavan-3-ols $(\mathrm{m} / \mathrm{z} 289)$ and some dimeric PAC-B types $(\mathrm{m} / \mathrm{z}$ 577). PCA analysis allowed a clear discrimination between the different cranberry products. The PAC composition of products $\mathbf{5}$ and $\mathbf{8}$ was close to the reference juice, whereas products $1,2,3,9$ were indiscriminate and contained less PACs. Product $\mathbf{7}$ was in the middle, with a PACs profile of lower quality than product $\mathbf{5}$ and $\mathbf{8}$ but higher than 1, 2, 3, 9. PAC-B type enriched profiles (products 4 and 6 ) corresponded to 
cranberry products that were mixed with grape or blueberry extracts (Table 1), two plants accumulating mainly PAC-B types.

It was important to note that UPLC-MS led almost to the same conclusions than HPTLCdensitometry analysis. Product $\mathbf{5}$ and $\mathbf{8}$ appeared as the best quality ingredient with indiscriminate PACs composition. This was in accordance with their PAC- $\mathrm{A}_{2} /$ Epicat. ratio closely related to each other and above 2, even though daily PACs dose was inferior to the requirement for product $\mathbf{8}$. This product would fulfil the daily PACs intake target of 36 $\mathrm{mg} /$ day, if the recommended dose is increased to 2 capsules per day. PAC-A $/$ /Epicat. ratio $\geq 2$ seemed to be more indicative of the good quality of cranberry ingredient than global PACs amount using DMAC.

\section{Conclusion}

Standardization of the quality control of commercial cranberry products is mandatory to assess the real impact of cranberry PACs on UTI and other medical diseases.

$$
\text { A standard quality control was proposed here: }
$$

1) sequential solid/liquid extractions using Acetone Mix and repeated until solid residue exhibited $A_{640 n m}<0.05$, after 20 min of contact with DMAC reagent;

2) Elimination of disturbing analytes using XAD-16 resin, to lead to a TPE extract;

3) BL-DMAC and HPTLC-densitometry analyses of resulting TPE.

HPTLC-densitometry protocol was optimized allowing the detection of low amount of PAC standards in low concentrated sample.

In the product set selected in this work, most of the products ( 7 of them) were found to contain poor quality PACs ingredient. Among them, product 6 exhibited high PAC-B $\mathrm{B}_{2}$ amount highlighting prevalence of inactive PACs in the product.

Product $\mathbf{5}$ and $\mathbf{8}$ was found to contain a high quality ingredient, characterized by a PAC$\mathrm{A}_{2} /$ Epicat. ratio $>2$. Product 8 would also fulfil the daily PACs intake target of $36 \mathrm{mg} / \mathrm{day}$, if 
the recommended dose was increase to 2 capsules per day. The PAC- $\mathrm{A}_{2} /$ Epicat. ratio $>2$ could

512 be used as an indicator of good quality ingredient. This ratio should become a reference

513

514

515

516

517

518

519

520

521

522

523

524

525

526

527

528

529 References

530

531

532

533

quality criteria beside the $36 \mathrm{mg}$ of global PACs/day.

UPLC-MS analyses coupled to multivariate analyses confirmed HPTLC-densitometry

results and in addition revealed the plural PAC composition of commercial products. Those

analyses validated the use of three standards and HPTLC protocol to assess the quality of the all PACs.

The next step would be the analysis of all products tested in clinical trials to try to correlate the PAC profile with clinical results.

\section{Acknowledgement}

The authors thank Dr E. Reich and E. Ceniviva from CAMAG application laboratory for kind help in mobile phase optimization. The authors thank also Pr Laurent Bazinet (INAF, Université Laval, Québec) who kindly provided crude cranberry juice.

\section{Funding source}

This research did not receive any specific grant from funding agencies in the public, commercial, or not-for-profit sector.

ANSES (2011) Avis de l'Agence nationale de sécurité sanitaire de l'alimentation, de l'environnement et du travail relatif à l'évaluation des effets potentiels de la canneberge dans le champ des infections urinaires communautaires. Anses - Saisine n 2010-SA-0214. 
Avorn, J., Monane, M., Gurwitz, J.H., Glynn, R.J., Choodnovskiy, I., \& Lipsitz, L.A. (1994)

Reduction of bacteriuria and pyuria after ingestion of cranberry juice. Journal of American Medical Association, 271: 751-4.

ANSM (2008) Recommandations de bonne pratique, Diagnostic et antibiothérapie des infections urinaires bactériennes communautaires chez l'adulte: cystite aiguë, cystite compliquée, cystite récidivante, pyélonéphrite aiguë simple, pyélonéphrite aiguë compliquée, prostatie aiguë, infections urinaires de la femme enceinte. AFFSAPS Juin 2008

Beerepoot, M.J., ter Riet, G., Nys, S., van der Wal, W.M., de Borgie, C.A., de Reijke, T.M., Prins, J.M., Koeijers, J., Verbon, A., Stobberingh, E., \& Geerlings, S.E.(2011) Cranberries vs antibiotics to prevent urinary tract infections a randomized double-blind non-inferiority trial in premenopausal women. Archive of Internal Medecine, 171(14), 1270-1278

Boudesocque, L., Dorat, J., Pothier, J., Gueiffier, A., \& Enguehard-Gueiffier, C. (2013) Highperformance thin-layer chromatography-densitometry: a step further for quality control of cranberry extracts, Food Chemistry, 136, 866-871.

EFSA (2009) Scientific opinion: Ocean Spray Cranberry Products® and urinary tract infection in women - Scientific substantiation of a health claim related to Ocean Spray Cranberry Products ${ }^{\circledR}$ and urinary tract infection in women pursuant to Article 14 of Regulation (EC) No 1924/2006, EFSA Journal, 943, 1-15.

Feinberg, M. (2007). Validation of analytical methods based on accuracy profiles. Journal of Chromatography A, 1158(1-2), 174-183. 
560 Girardot M., Guerineau A., Boudesocque L., Costa D., Bazinet L., Enguehard-Gueiffier C., \& 561 Imbert C. (2014) Promising results of cranberry in the prevention of oral Candida biofilms. 562 Pathogens and Disease, 70, 432-439.

563

564

565

566

567

568

569

570

571

572

573

574

575

576

577

578

579

580

581

582

583

Gu, L., Kelm, M. A., Hammerstone, J. F., Beecher, G., Holden, J., Haytowitz, D., Gebhardt, S., \& Prior, R. L. (2004). Concentrations of proanthocyanidins in common foods and estimations of normal consumption. The Journal of Nutrition, 134(3), 613-617.

Howell, A. B. (2007). Bioactive compounds in cranberries and their role in prevention of urinary tract infections. Molecular Nutrition \& Food Research, 51(6), 732-737.

Hümmer, W., \& Schreier, P. (2008). Analysis of proanthocyanidins. Molecular Nutrition \& Food Research, 52(12), 1381-1398.

Iswaldi, I., Gomez-Caravaca, A. M., Arraez-Roman, D., Uberos, J., Lardon, M., Segura-

Carretero, A., \& Fernandez-Gutierrez, A. (2012). Characterization by high-performance liquid chromatography with diode-array detection coupled to time-of-flight mass spectrometry of the phenolic fraction in a cranberry syrup used to prevent urinary tract diseases, together with a study of its antibacterial activity. Journal of Pharmaceutical and Biomedical Analysis, 58, 3441.

Jepson, R.G., Williams, G., \& Craig, J.C. (2012) Cranberries for preventing urinary tract infections (Review). Cochrane Database of Systematic Reviews, 10. Art. No.: CD001321. 
587

588

589

590

591

592

593

594

595

596

597

598

599

600

601

602

603

604

605

606

607

Juthani-Mehta, M., Perley, L., Chen, S., Dziura, J., \& Gupta, K. (2010) Feasibility of cranberry capsule administration and clean-catch urine collection in long term care residents, Journal of American Geriatric Society, 58 (10), 2028-2030.

Kimura, H., Ogawa, S., Akihiro, T., \& Yokota, K. (2011) Structural analysis of A-type or Btype highly polymeric proanthocyanidins by thiolytic degradation and the implication in their inhibitory effects on pancreatic lipase. Journal of Chromatography A, 1218, 7704-7712.

Kowalska, K., \& Olejnik A. (2016) Beneficial effects of cranberry in the prevention of obesity and related complications: Metabolic syndrome and diabetes - A review. Journal of Functional Food, 20, 171-181.

Krueger, C. G., Chesmore, N., Chen, X., Parker, J., Khoo, C., Marais, J. P.J.,

Shanmuganayagam, D., Crump, P., \& Reed, J. D. (2016) Critical reevaluation of the 4(dimethylamino)cinnamaldehyde assay: Cranberry proanthocyanidin standard is superior to procyanidin A2 dimer for accurate quantification of proanthocyanidins in cranberry products. Journal of Functional Foods, 22, 13-19. 316 (18), 1873-1874.

Lee, J. (2013) Proanthocyanidin $A_{2}$ purification and quantification of American cranberry (Vaccinium macrocarpon Ait.) products. Journal of Functional Food, 5, 144-153.

Nicolle, L.E. (2016) Cranberry for prevention of urinary tract infection? Time to move on. Journal of American Medical Association, 316 (18), 1873-1874 
616

620

621

622

Pragati, A., Manisha, T., \& Prakruti, A. (2014) Development and validation of high performance thin layer chromatographic (HPTLC) method for estimation of tapentadol hydrochloride in bulk and its tablet dosage form. International Journal of Pharmaceutical Sciences and Research, 5(7), 2651-2656

Prior, R. L., Fan, E., Ji, H., Howell, A., Nio, C., Payne, M. J., \& Reed, J. (2010) Multilaboratory validation of a standard method for quantifying proanthocyanidins in cranberry powders. Journal of the Science of Food and Agriculture, 90(9), 1473-1478.

Rajasree, R.S., Radha, K., Shyni, B., Girija, K.N., \& Nair, A.K.C. (2013) Estimation of lomefloxacin hydrochloride in bulk and tablet dosage form by HPTLC method. Hygeia: Journal for drugs and medicine, 5 (1), 141-147.

Rodriguez-Mateos, A., Feliciano, R. P., Boeres, A., Weber, T., Nunes dos Santos, C., Ventura, M. R., \& Heiss, C. (2016) Cranberry (poly)phenol metabolites correlate with improvements in vascular function: A double-blind, randomized, controlled, dose-response, crossover study. Molecular Nutrition and Food Research, 00, 1-11.

Rozoy, E., Boudesocque, L., \& Bazinet, L. (2015) Deacidification of cranberry juice by electrodialysis with bipolar membranes. Journal of Agricultural and Food Chemistry., 63(2), 642-651.

Sánchez-Patán, F., Bartolome, B., Martín-Alvaréz, P. J., Anderson, M., Howell, A., \& Monagas, M. (2012). Comprehensive assessment of the quality of commercial cranberry 
632 products. Phenolic characterization and in vitro bioactivity. Journal of Agricultural and Food 633 Chemistry, 60(13), 3396-3408.

634

635 
637 Figure 1: General sample preparation procedure for BL-DMAC and HPTLC-densitometry 638 analysis.

639 Figure 2: HPTLC profiles of product 5, 8, 7, 1 and 6. Mobile phase: methylene chloride/ 640 EtOAc/ formic acid (6:10:2, v/v), staining reagent sulfuric anisaldehyde. Sample amounts 641 were doubled compared to UV densitometric measurement.

642 Figure 3: PCA core plot (a) and loading plot (b) on UPLC-MS-based PAC data from different 643 cranberry products. Variables in score plot were colored according to cranberry extracts.

644 Variables in the loading plot were colored according to PAC types; flavan-3-ols monomers $645(\mathrm{~m} / \mathrm{z} 289$, green), dimeric PAC-A types $(\mathrm{m} / \mathrm{z}, 575$, blue), trimeric PAC-A types $(\mathrm{m} / \mathrm{z}, 863$, 646 yellow), dimeric PAC-B types $(\mathrm{m} / \mathrm{z}, 577$, red).

647

648

649

650

651

652

653

654

655

656 
658 Table 1: commercial products selected for the study

\begin{tabular}{llll}
\hline Product & Presentation & Daily/dose & PACs and anthocyanin ingredients \\
\hline $\mathbf{1}$ & Sticks & 2 sticks & Cranberry, green tea \\
$\mathbf{2}$ & Syrup & 10 to $20 \mathrm{~mL}$ & Cranberry juice, Heather, Hibiscus \\
$\mathbf{3}$ & Capsules & 1 à 2 capsules & Cranberry extract powder \\
$\mathbf{4}$ & Capsules & 2 capsules & Cranberry extract, Heather extract, Blueberry extract \\
$\mathbf{5}$ & Capsules & 2 capsules & Cranberry extract and concentrated juice \\
$\mathbf{6}$ & Capsules & 2 capsules & Cranberry concentrated juice, grape seed extract \\
$\mathbf{7}$ & Capsules & 4 capsules & Cranberry extract \\
$\mathbf{8}$ & Capsules & 1 capsule & Cranberry extract \\
$\mathbf{9}$ & Tablets & 4 tablets & Cranberry extract, Hibiscus extract \\
$\mathbf{1 0}$ & Capsules & 2 capsules & Cranberry extract \\
\hline
\end{tabular}

659

660

661

662

663

664

665

666

667

668

669

670

671

672

673

674

675

676

677

678

679 
Table 2 Solid/liquid extraction optimization data

\begin{tabular}{|c|c|c|c|c|c|c|}
\hline Product & Daily dose & Extraction solvent & $\begin{array}{c}\text { Repetitions } \\
n=3\end{array}$ & $\begin{array}{c}\text { TPE } \\
\text { Extraction } \\
\text { yield (\%) } \\
n=3\end{array}$ & $\begin{array}{c}\text { \%(w/w) PACs } \\
\text { in TPE } \\
\text { (BL-DMAC) } \\
n=9\end{array}$ & $\begin{array}{c}\text { Total PACs } \\
\text { (mg) in daily } \\
\text { dose } \\
n=9\end{array}$ \\
\hline & & & & & & \\
\hline \multirow{3}{*}{3} & \multirow{3}{*}{2 capsules } & Water & 12 & $26.3 \pm 0.1$ & $2.9 \pm 0.0$ & $6.6 \pm 0.1^{a}$ \\
\hline & & Acetone Mix & 10 & $13.9 \pm 0.3$ & $3.6 \pm 0.0$ & $4.4 \pm 0.0^{\mathrm{b}}$ \\
\hline & & $\mathrm{MeOH} 0.1 \% \mathrm{HCl}$ & 12 & $18.0 \pm 0.3$ & $3.9 \pm 0.1$ & $5.9 \pm 0.1^{\mathrm{a}}$ \\
\hline \multirow{3}{*}{4} & \multirow{3}{*}{2 capsules } & Water & 4 & $16.8 \pm 0.2$ & $3.7 \pm 0.0$ & $3.8 \pm 0.0^{\mathrm{a}}$ \\
\hline & & Acetone Mix & 3 & $26.6 \pm 0.6$ & $3.3 \pm 0.1$ & $5.4 \pm 0.1^{b}$ \\
\hline & & $\mathrm{MeOH} 0.1 \% \mathrm{HCl}$ & 3 & $24.2 \pm 0.4$ & $3.8 \pm 0.0$ & $5.8 \pm 0.1^{\mathrm{b}}$ \\
\hline \multirow{3}{*}{5} & \multirow{3}{*}{2 capsules } & Water & 5 & $27.1 \pm 0.3$ & $18.3 \pm 0.2$ & $44.0 \pm 0.5^{\mathrm{a}}$ \\
\hline & & Acetone Mix & 5 & $27.3 \pm 0.5$ & $14.8 \pm 0.1$ & $36.0 \pm 0.2^{b}$ \\
\hline & & $\mathrm{MeOH} 0.1 \% \mathrm{HCl}$ & 5 & $24.9 \pm 0.3$ & $17.1 \pm 0.1$ & $37.5 \pm 0.2^{c}$ \\
\hline \multirow{3}{*}{6} & \multirow{3}{*}{2 capsules } & Water & 3 & $37.9 \pm 1.7$ & $13.3 \pm 0.2$ & $40.4 \pm 1.7^{\mathrm{a}}$ \\
\hline & & Acetone Mix & 4 & $47.8 \pm 1.8$ & $15.6 \pm 0.1$ & $62.3 \pm 1.3^{b}$ \\
\hline & & $\mathrm{MeOH} 0.1 \% \mathrm{HCl}$ & 4 & $40.1 \pm 1.0$ & $15.3 \pm 0.3$ & $49.7 \pm 2.0^{\mathrm{c}}$ \\
\hline \multirow{3}{*}{7} & \multirow{3}{*}{4 capsules } & Water & 5 & $23.4 \pm 0.1$ & $7.2 \pm 0.3$ & $30.7 \pm 1.1^{\mathrm{a}}$ \\
\hline & & Acetone Mix & 5 & $23.6 \pm 0.0$ & $8.3 \pm 0.1$ & $36.0 \pm 0.3^{b}$ \\
\hline & & $\mathrm{MeOH} 0.1 \% \mathrm{HCl}$ & 5 & $22.7 \pm 0.1$ & $8.7 \pm 0.1$ & $36.0 \pm 0.2^{\mathrm{b}}$ \\
\hline \multirow{3}{*}{8} & \multirow{3}{*}{1 capsule } & Water & 5 & $38.0 \pm 0.8$ & $18.6 \pm 0.2$ & $16.2 \pm 0.4^{\mathrm{a}}$ \\
\hline & & Acetone Mix & 5 & $41.8 \pm 0.4$ & $15.9 \pm 0.2$ & $15.2 \pm 0.2^{\mathrm{a}}$ \\
\hline & & $\mathrm{MeOH} 0.1 \% \mathrm{HCl}$ & 5 & $41.5 \pm 0.5$ & $19.2 \pm 0.2$ & $18.8 \pm 0.4^{\mathrm{b}}$ \\
\hline \multirow{3}{*}{9} & \multirow{3}{*}{4 tablets } & Water & 18 & $16.5 \pm 0.7$ & $4.4 \pm 0.1$ & $20.9 \pm 1.0^{\mathrm{a}}$ \\
\hline & & Acetone Mix & 18 & $20.1 \pm 0.4$ & $3.6 \pm 0.1$ & $23.2 \pm 0.8^{b}$ \\
\hline & & $\mathrm{MeOH} 0.1 \% \mathrm{HCl}$ & 18 & $20.3 \pm 0.1$ & $3.7 \pm 0.1$ & $23.9 \pm 0.5^{b}$ \\
\hline \multirow{3}{*}{10} & \multirow{3}{*}{2 capsules } & Water & 14 & $13.9 \pm 0.2$ & $10.7 \pm 0.1$ & $11.6 \pm 0.7^{\mathrm{a}}$ \\
\hline & & Acetone Mix & 10 & $13.9 \pm 0.1$ & $10.2 \pm 0.2$ & $11.1 \pm 0.2^{\mathrm{a}}$ \\
\hline & & $\mathrm{MeOH} 0.1 \% \mathrm{HCl}$ & 10 & $13.1 \pm 0.2$ & $10.8 \pm 0.4$ & $11.1 \pm 0.6^{\mathrm{a}}$ \\
\hline
\end{tabular}
product 
691 based on the recommended dose

\begin{tabular}{ccccccc}
\hline & & BL-DMAC & \multicolumn{3}{c}{ HPTLC-densitometry } & \\
Product & Daily dose & $\begin{array}{c}\text { Total PACs } \\
(\mathrm{mg})^{a}\end{array}$ & Epicat. $(\mathrm{mg})^{b}$ & ${\text { PAC- } \mathrm{A}_{2}(\mathrm{mg})^{b}}^{b}$ & ${\text { PAC- } \mathrm{B}_{2}(\mathrm{mg})^{b}}^{\text {PAC- }_{2} / \text { Epicat. }}$ & ratio \\
& & $n=9$ & $n=9$ & $n=9$ & $n=9$ & $n=9$ \\
\hline Juice & $300 \mathrm{ml}$ & $35.2 \pm 0.2$ & $3.67 \pm 0.02$ & $8.73 \pm 0.04$ & n.d. & 2.38 \\
$\mathbf{1}$ & 2 sticks & $62.4 \pm 0.8$ & $1.50 \pm 0,05$ & $n . d$. & n.d. & 0 \\
$\mathbf{2}$ & $20 \mathrm{~mL}$ & $7.0 \pm 0.2$ & $n . d$. & $0.66 \pm 0.01$ & n.d. & $\infty$ \\
$\mathbf{3}$ & 2 capsules & $4.4 \pm 0.0$ & $0.50 \pm 0.01$ & $0.51 \pm 0.01$ & n.d. & 1.03 \\
$\mathbf{4}$ & 2 capsules & $5.4 \pm 0.1$ & $0.10 \pm 0.00$ & $0.05 \pm 0.00$ & n.d. & 0.46 \\
$\mathbf{5}$ & 2 capsules & $36.0 \pm 0,2$ & $2.15 \pm 0.03$ & $5.07 \pm 0.08$ & n.d. & 2.36 \\
$\mathbf{6}$ & 2 capsules & $62.3 \pm 1.3$ & $1.65 \pm 0.05$ & $0.82 \pm 0.02$ & $8.40 \pm 0.14$ & 0.50 \\
& & & $2.18 \pm 0.06(\text { Cat. })^{*}$ & & \\
$\mathbf{7}$ & 4 capsules & $36.0 \pm 0.3$ & $1.39 \pm 0.02$ & $1.48 \pm 0.04$ & n.d. & 1.06 \\
$\mathbf{8}$ & 1 capsule & $15.2 \pm 0.2$ & $0.87 \pm 0.01$ & $1.83 \pm 0.02$ & n.d. & 2.10 \\
$\mathbf{9}$ & 4 tablets & $23.2 \pm 0.8$ & $0.48 \pm 0.01$ & $0.54 \pm 0.02$ & n.d. & 1.13 \\
$\mathbf{1 0}$ & 2 capsules & $11.1 \pm 0.2$ & $0.32 \pm 0.01$ & $0.32 \pm 0.01$ & n.d. & 1.02 \\
\hline
\end{tabular}

692

"Cat: catechin; n.d.: not determined, $A U C$ lower than $L O Q$

693

694 